\title{
ANALISIS BEBAN KERJA MENTAL KARYAWAN MENGGUNAKAN METODE NASA TLX (Studi Kasus: PT. Universal Tekno Reksajaya Pekanbaru, Riau)
}

\author{
Zayyinul Hayati Zen"), Ardi Adrian' \\ Program Studi Teknik Industri Universitas Muhammadiyah Riau \\ Jalan Tuanku Tambusai Ujung, Simpang Komersil Arengka (SKA), Kecamatan Tampan, Kelurahan \\ Delima, Delima, Kota Pekanbaru, Riau 28291 \\ e-mail :zayyinulhayati@umri.ac.id
}

\begin{abstract}
PT. Universal Tekno Reksajaya is a company engaged in remanufacturing heavy equipment components in Indonesia. Of course this serves as a rejuvenation of machine components into components that can be reused with quality equivalent to new products. PT Universal Tekno Reksajaya is a subsidiary of PT United Tractors Tbk. with the location of the first (and second) plants built at the time being the Pekanbaru and Jakarta plants. The number of jobs desk jobs in the General Over Houl (GOH) section raises complaints for workers related to work pressure, excessive working hours, the emergence of boredom and boredom towards work so as to make employee productivity decline. Therefore the mental workload analysis of workers is needed using the NASA TLX method. After an analysis of the General Over Houl (GOH) section, the results were very high mental workload of workers. Thus the need for recommendations related to the addition of human resources to divide so many jobs desk to be lighter, hold motivation sharing to restore employee morale and entertainment activities such as ice breaking games and sports facilities to restore employee fitness
\end{abstract}

Keywords: Mental Workload, NASA TLX

\begin{abstract}
Abstrak
PT. Universal Tekno Reksajaya adalah sebuah perusahaan yang bergerak dibidang remanufacturing komponen-komponen alat berat di Indonesia. Tentunya ini berfungsi sebagai peremajaan komponenkomponen alat berat menjadi komponen yang dapat digunakan kembali dengan kualitas setara dengan produk baru. PT Universal Tekno Reksajaya merupakan salah satu anak perusahaan PT United Tractors Tbk. dengan lokasi plant pertama (dan kedua) yang dibangun pada saat itu adalah plant Pekanbaru dan Jakarta. Banyaknya jobs desk pekerjaan pada section General Over Houl (GOH) menimbulkan keluhan bagi pekerja terkait dengan tekanan kerja, jam kerja yang berlebihan, munculnya rasa bosan dan jenuh terhadap pekerjaan sehingga membuat produktivitas karyawan menjadi menurun. Maka dari itu di perlukan analisis beban kerja mental terhadap pekerja menggunakan metode NASA TLX. Setelah dilakukan analisis terhadap pekerja section General Over Houl $(\mathrm{GOH})$ didapat hasil sangat tingginya beban kerja mental pekerja. Dengan itu perlunya rekomendasi terkait dengan penambahan SDM untuk membagi jobs desk yang begitu banyak agar lebih ringan, mengadakan sharing motivasi untuk mengembalikan semangat kerja karyawan dan kegiatan-kegiatan hiburan seperti ice breaking games dan sarana olah raga untuk mengembalikan kebugaran karyawan.
\end{abstract}

Kata Kunci: Beban Kerja Mental, NASA TLX

\section{Pendahuluan}

PT. Universal Tekno Reksajaya merupakan sebuah perusahaan remanufacturing komponenkomponen alat berat yang berfungsi sebagai peremajaan komponen-komponen alat berat menjadi komponen yang dapat digunakan kembali dengan kualitas setara dengan produk baru. Sehingga membantu menekan biaya operasional pelanggan. PT. Universal Tekno Reksajaya merupakan salah satu anak perusahaan PT United Tractors Tbk. dengan lokasi plant pertama (dan kedua) yang dibangun pada saat itu adalah plant Pekanbaru dan Jakarta. 
PT. Universal Teknologi Reksajaya ini menerima pelayanan remanufacturing tidak hanya yang berada di daerah Pekanbaru saja, tetapi juga menerima dari kawasan Sumatera. Dengan kondisi pekerjaan yang menuntut agar karyawan dapat menyelesaikan pekerjaan dengan kualitas yang baik dan tepat waktu sehingga mempunyai beban tersendiri bagi karyawan untuk dapat menyelesaikannya. Berdasarkan hal tersebut karyawan section General Over Houl (GOH) yang hanya terdiri dari 6 orang yang dikoordinir oleh seorang leader melakukan berbagai macam upaya untuk dapat menyelesaikannya. Namun dalam kenyataan target ditetapkan perusahaan belum sepenuhnya terpenuhi dan hal itulah yang memicu munculnya stres kerja karyawan terhadap beban kerja yang diberikan, karena mereka merasakan beban kerja yang diberikan belum sesuai dengan kapasitasnya. Berdasarkan pengecekan di lapangan dan hasil wawancara karyawan di section General Over Houl (GOH) terdapat beberapa keluhan diantaranya adalah :

Tabel 1.1. Rekap Keluhan Karyawan pada Section General Over Houl (GOH)

\begin{tabular}{|c|l|}
\hline No & \multicolumn{1}{|c|}{ Jenis Keluhan } \\
\hline 1 & Merasakan tekanan kerja yang cukup tinggi \\
\hline 2 & Merasakan bosan \\
\hline 3 & Motivasi kerja kurang \\
\hline 4 & Kepala pusing dan muncul rasa malas untuk bekerja \\
\hline 5 & Jobs Desk yang terlalu banyak \\
\hline 6 & Sering lembur \\
\hline
\end{tabular}

Sumber: Kerja praktek, 2019

Berdasarkan tabel 1.1 rekapan keluhan karyawan section General Over Houl (GOH) di Universal Tekno Reksajaya terlihat bagaimana bentuk tekanan dan beban kerja mental. Dalam hal ini, perusahaan perlu mengetahui dan mengambil tindakan terhadap hal tersebut. Sebab, jika terus dibiarkan beban kerja yang berlebihan akan menyebabkan penurunan kinerja karyawan dan selanjutnya akan menurunkan produktifitas perusahaan karena sumber daya manusia merupakan aset penting yang berperan sangat penting untuk mewujudkan tujuan perusahaan

Oleh karena itu diperlukan analisis beban kerja mental terhadap pekerja di section General Over Houl (GOH) di PT. Universal Tekno Reksajaya menggunakan metode National Aeronautics and Space Administration Task Load Index (NASA TLX). Kerja praktek ini diharapkan dapat membantu perusahaan dalam mengukur beban kerja mental yang lebih akurat dengan spesifikasi beban kerja mental yang sudah ada pada metode NASA TLX. Sehingga dapat meningkatkan efisiensi sumber daya manusia pada PT. Universal Tekno Reksajaya.

Pengukuran beban kerja mental dapat dilakukan dengan dua cara yaitu pengukuran secara objektif dapat dilakukan dengan beberapa anggota tubuh antara lain denyut jantung, kedipan mata dan ketegangan otot. Pengukuran beban kerja mental secara subjektif merupakan teknik pengukuran yang paling banyak digunakan karena mempunyai tingkat validitas yang tinggi dan bersifat langsung dibandingkan dengan pengukuran lain. Pengukuran beban kerja mental secara subjektif memiliki tujuan yaitu untuk menentukan skala pengukuran terbaik berdasarkan perhitungan eksperimental, menentukan perbedaan skala untuk jenis pekerjaan dan mengidentifikasi faktor beban kerja yang berhubungan secara langsung dengan beban kerja mental. Faktor lain yang mempengaruhi beban kerja mental seseorang dalam mengenai suatu pekerjaan antara lain jenis pekerjaan, situasi kerjaan waktu respon, waktu penyelesaian yang tersedia dan faktor individu tingkat motivasi, keahlian, kelelahan, kejenuhan dan toleransi performansi yang diijinkan [1].

The National Aeronautical and Space Administration Task Load Index (NASA TLX) dikembangkan oleh Sandra G. Dari NASA Ames Research Center dan Lowell E. Staveland dari San Jose State University pada tahun 1981. Metode ini dikembangkan berdasarkan munculnya kebutuhan pengukuran subjektif yang terdiri dari skala sembilan faktor (kesulitan tugas, tekanan waktu, jenis aktivitas, usaha fisik, usaha mental, performansi, frustasi, stres dan kelelahan). Dari sembilan faktor ini disederhanakan lagi menjadi enam yaitu Mental demand, Physical demand, Temporal (time) demand, Performance, Effort dan Frustration[2].

Contoh Kartu Perbandingan Berpasangan dari Metode NASA TLX

\begin{tabular}{|c|c|c|}
\hline $\begin{array}{c}\text { Kebutuhan Waktu } \\
\text { ATAU } \\
\text { Tingkat Frustasi }\end{array}$ & $\begin{array}{c}\text { Kebutuhan Fisik } \\
\text { ATAU }\end{array}$ & $\begin{array}{c}\text { Performansi } \\
\text { ATAU } \\
\text { Tingkat Frustasi }\end{array}$ \\
\hline $\begin{array}{c}\text { Kebutuhan Waktu } \\
\text { ATAU }\end{array}$ & Tingkat Usaha & Tingkat Usaha \\
Tingkat Usaha & ATAU & ATAU \\
Kebutuhan Mental & Performansi & Kebutuhan Fisik \\
ATAU & ATAU & ATAU \\
Tingkat Usaha & Kebutuhan Mental & Kebutuhan Mental \\
\hline Kebutuhan Mental & Performansi & Tingkat Frustasi \\
ATAU & ATAU & ATAU \\
Kebutuhan Fisik & Kebutuhan Waktu & Tingkat Usaha \\
\hline Kebutuhan Waktu & Kebutuhan Fisik & Kebutuhan Fisik \\
ATAU & ATAU & ATAU \\
Kebutuhan Mental & Kebutuhan Waktu & Tingkat Frustasi \\
\hline
\end{tabular}

Gambar 1 Perbandingan berpasangan 


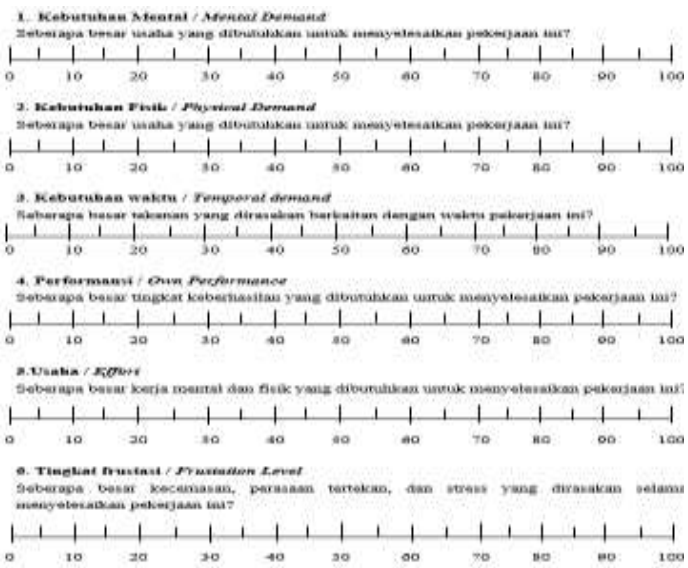

Gambar 2. Mental demand

Adapun tujuan dari pekasanaan kerja praktek yakni :

1. Menghitung rating beban kerja mental dengan mengunakan metode NASA TLX.

2. Memberikan rekomendasi perbaikan kepada perusahaan tersebut untuk mengurangi tingginya beban kerja mental

\section{Metodologi}

Dalam pengukuran beban kerja mental dengan menggunakan metode NASA TLX langkah langkah yang harus dilakukan adalah :

1) Pembobotan

Pada proses ini responden diminta untuk melingkari salah satu dari dua indikator yang dirasakan lebih dominan menimbulkan beban kerja mental terhadap pekerjaan tersebut. Kuesioner yang diberikan berbentuk perbandingan berpasangan yang terdiri dari 15 kuesioner perbandingan berpasangan. Dari dua kuesioner ini dihitung jumlah tally dari setiap indikator yang dirasakan paling berpengaruh. Jumlah tally menjadi bobot untuk tiap indikator beban mental.

\section{2) Pemberian Rating}

Pada proses ini responden diminta memberikan rating pada setiap indikator beban mental. Rating yang diberikan adalah subjektif tergantung pada beban mental yang dirasakan oleh responden.

Untuk mendapatkan skor beban mental NASA TLX, bobot rating untuk setiap indikator dikalikan kemudian dijumlahkan dan dibagi 15 (jumlah perbandingan berpasangan).

3) Perhitungan Nilai Rata-rata WWL

Dari hasil perbandingan berpasangan tersebut akan didapatkan nilai bobot yang nantinya akan menentukan rata-rata weighted work load (WWL) yang diformulasikan sebagai:

Mean $\mathrm{WWL}=\frac{\sum \text { vilai } \times \text { Babot Faksor }}{\text { Jumlab Botot }}$
4) Pengkategorian Penilaian Beban Kerja Kategori penilaian beban kerja terdiri dari 5 tingkatan [3], yaitu :

\begin{tabular}{ccc}
\hline No & Kategori & Skala Interval \\
1 & Rendah & $0-9$ \\
2 & Sedang & $10-29$ \\
3 & Agak Tinggi & $30-49$ \\
4 & Tinggi & $50-79$ \\
5 & Sangat Tinggi & $80-100$ \\
\hline
\end{tabular}

\section{Hasil dan Pembahasan}

\subsection{Perhitungan Skor setiap skala}

Pada pengumpulan data yang dilakukan, data diperoleh melalui wawancara dan observasi secara langsung kepada pekerja section General Over Houl (GOH) di PT. Universal Tekno Reksajaya. Selain itu pengumpulan data juga dilakukan melalui penyebaran dan pengumpulan kuisioner NASA TLX kepada karyawan.

Tabel 3.1. Rekapitulasi Hasil Pembobotan

\begin{tabular}{|c|c|c|c|c|c|c|c|c|}
\hline \multirow[b]{2}{*}{$\mathrm{NO}$} & \multirow{2}{*}{ Responden } & \multicolumn{6}{|c|}{ Indikator } & \multirow{2}{*}{ TOTAL } \\
\hline & & $\mathrm{MD}$ & $\mathrm{PD}$ & $\mathrm{TD}$ & $\mathrm{P}$ & $\bar{E}$ & FL & \\
\hline 1 & Syafriadi & 2 & 1 & 3 & 5 & 4 & - & 15 \\
\hline 2 & Lauren & 4 & 2 & 1 & 5 & 3 & - & 15 \\
\hline 3 & Akmal & 3 & 1 & 2 & 5 & 4 & - & 15 \\
\hline 4 & Bayu & 2 & 3 & 2 & 4 & 2 & 2 & 15 \\
\hline 5 & Bobi & 4 & 2 & 1 & 5 & 3 & - & 15 \\
\hline 6 & Dika & 2 & - & 3 & 4 & 3 & 3 & 15 \\
\hline
\end{tabular}

Sumber : Data Kuesioner GOH UTR, 2019.

\subsection{Pemberian Rating}

Pemberian rating dilakukan setelah pembobotan. Pada tahap ini berskala 0-100 yang diberikan pada setiap indikator yang sesuai dengan apa yang dirasakan oleh operator.

Tabel 3.2. Rekapitulasi Hasil Peratingan

\begin{tabular}{|c|l|c|c|c|c|c|c|}
\hline \multirow{2}{*}{ NO } & \multirow{2}{*}{ Responden } & \multicolumn{7}{|c|}{ Indikator } \\
\cline { 3 - 8 } & & MD & PD & TD & P & E & FL \\
\hline 1 & Syafriadi & 80 & 80 & 90 & 90 & 90 & 60 \\
\hline 2 & Lauren & 100 & 100 & 80 & 90 & 90 & 40 \\
\hline 3 & Akmal & 90 & 90 & 80 & 90 & 90 & 80 \\
\hline 4 & Bayu & 90 & 100 & 50 & 90 & 90 & 50 \\
\hline 5 & Bobi & 50 & 80 & 50 & 100 & 100 & 50 \\
\hline 6 & Dika & 90 & 40 & 70 & 100 & 80 & 70 \\
\hline
\end{tabular}

Sumber : Data Kuesioner GOH UTR, 2019.

\subsection{Perhitungan Skor dan rata-rata WWL}

Pada perhitungan skor beban kerja mental pada karyawan section General Over Houl (GOH) di PT. Universal Tekno Reksajaya.

a. Mental Deman (MD)

Produk $=$ Bobot $x$ Rating

$$
\begin{aligned}
& =2 \times 80 \\
& =160
\end{aligned}
$$


b. Physical Deman (PD)

Produk $=$ Bobot $x$ Rating

$$
\begin{aligned}
& =1 \times 80 \\
& =80
\end{aligned}
$$

c. Rata-rata WWL $=\Sigma \underline{W W L}$

$$
\begin{aligned}
& =\frac{1230}{15} \\
& =82
\end{aligned}
$$

\begin{tabular}{|c|c|c|c|c|}
\hline \multicolumn{5}{|c|}{ Syafriadi } \\
\hline No & Indikator & Bobot & Rating & Nilai Produk \\
\hline 1 & Kebutuhan Mental (MD) & 2 & 80 & 160 \\
\hline 2 & Kebutuhan Fisik (PD) & 1 & 80 & 80 \\
\hline 3 & Kebutuhan Waktu (TD) & 3 & 90 & 270 \\
\hline 4 & Performansi (P) & 5 & 90 & 450 \\
\hline 5 & Usaha (EF) & 3 & 90 & 270 \\
\hline 6 & Tingkat Frustasi (FL) & - & 60 & 0 \\
\hline & & & WWL & 1230 \\
\hline & & & $\begin{array}{c}\text { Rata-rata WWL } \\
\text { (Weighted } \\
\text { Workload) }\end{array}$ & 82 \\
\hline
\end{tabular}

Tabel 3.3. Hasil Perhitungan Skor dan rata-rata WWL Syafriadi

Sumber : Data Kuesioner GOH UTR, 2019.

3.4 Pengkategorian Penilaian Beban Kerja

Berikut hasil dari pengkategorian penilaian beban kerja pada karyawan section General Over Houl (UTR).

Tabel 3.4. Rekapitulasi Hasil Perhitungan dan Rata-rata WWL Karyawan.

\begin{tabular}{|c|l|c|c|c|}
\hline No & Responden & $\begin{array}{c}\text { Indikator Paling } \\
\text { Berpengaruh }\end{array}$ & $\begin{array}{c}\text { Rata-rata } \\
\text { WWL }\end{array}$ & Kategori \\
\hline 1 & Syafriadi & Performansi (P) & 82 & Sangat Tinggi \\
\hline 2 & Lauren & Performansi (P) & 93,33 & Sangat Tinggi \\
\hline 3 & Akmal & Performansi (P) & 88,67 & Sangat Tinggi \\
\hline 4 & Bayu & Performansi ( P) & 81,33 & Sangat Tinggi \\
\hline 5 & Bobi & Performansi (P) & 80,67 & Sangat Tinggi \\
\hline 6 & Dika & Performansi (P) & 82,67 & Sangat Tinggi \\
\hline
\end{tabular}

Sumber : Data Kuesioner GOH UTR, 2019.

Bedasarkan pemaparan diatas rekomendasi yang tepat yang dapat diberikan kepada perusahaan terkait dengan beban kerja mental di section General Over Houl (GOH) adalah :

1) Melakukan penambahan SDM dibagian section General Over Houl (GOH) agar dapat membagi jobs desk pekerjaan yang sangat banyak supaya beban kerja dapat terasa lebih ringan.

2) Melakukan rotasi kerja karyawan untuk mengurangi rasa bosan dan jenuh terhadap pekerjaan saat ini.

3) Melakukan sharing motivasi terhadap karyawan untuk menumbuhkan semangat kerja karyawan.

4) Membuat acara hiburan, seperti ice breaking games. Selain untuk mengurangi tingkat kejenuhan selama bekerja itu juga akan membuat kekompakan antara pekerja yang satu dengan pekerja yang lainnya.
5) Menyediakan fasilitas olah raga bagi karyawan seperti futsal dan olah raga badminton untuk mengurangi tingkat stres dan kejenuhan karyawan terhadap pekerjaan.

\section{Simpulan}

kesimpulan dari pengukuran beban kerja mental ini yaitu sebagai berikut :

1) Karyawan section General Over Houl (GOH) di PT. Universal Tekno Reksajaya memiliki nilai rata-rata yang tinggi diatas 80 . Seperti berikut Syafriadi dengan nilai rata-rata 82 , Akmal dengan nilai rata-rata 88,67, Bayu dengan nilai rata-rata 81,33 , Bobi dengan nilai rata-rata 80,67 , Dika dengan nilai rata-rata 82,67 dan nilai rata-rata paling tinggi ditemukan pada karyawan atas nama Lauren dengan nilai rata-rata yaitu 93,33.

2) Rekomendasi perbaikan yang diberikan untuk mengurangi beban kerja mental berupa penambahan SDM agar dapat membagi jobs desk yang begitu banyak supaya beban kerja terasa lebih ringan, sharing motivasi untuk menumbuhkan semangat kerja karyawan, melakukan rotasi karyawan dengan harapan dapat mengurangi rasa bosan dan jenuh terhadap pekerjaan, membuat acara hiburan seperti ice breaking games untuk mengurangi rasa bosan dan kejenuhan terhadap pekerjaan selain itu juga untuk menjaga kekompakan antara karyawan satu dengan yang lainnya dan menyediakan fasilitas olah raga seperti futsal atau badminton untuk mengembalikan kebugaran karyawan saat bekerja.

\section{Daftar Pustaka}

[1] Mariawati, Ade Sri. Penilaian Beban Kerja Psikologis Operator Stasiun Kerja Menggunakan Metode National Aeronautics and Space AdministrationTask Load Index. Jurusan Teknik Industri Fakultas Teknik Universitas Sunan Ageng Tirtayasa. Banten. 2013: 101-104.

[2] Mutia, Mega. Pengukuran Beban Kerja Fisiologis dan Psikologis pada Operator Pemetikan Teh dan Operator Produksi Teh Hijau di PT Mitra Kerinci. Jurnal Optimasi Sistem Industri, Jurusan Teknik Industri Fakultas Teknin Universitas Andalas, Padang, Vol. 13 No. 1, April 2014. 503-517.

[3] Nurcahyo, Heru. Ilmu Kesehatan untuk Sekolah Menengah Kejuruan Jilid 2, Direktorat Pembinaan Sekolah Menengah Kejuruan Direktorat Jendral Manajemen 
Pendidikan Dasar dan Menengah Departemen

Pendidikan Nasional, Jakarta. 2008, 440 Hal. 